\title{
Expectativas dos alunos do curso de enfermagem acerca da disciplina de Enfermagem Neonatológica
}

\author{
Students expectations about the Neonatology Nursing course
}

\section{Expectativas de los alumnos del curso de graduación en enfermería cuanto a la disciplina de Enfermería Neonatológica}

\author{
Maria Isabel Ruiz Beretta', Silvia Helena Zem Mascarenhas", Giselle Dupas ${ }^{\text {III }}$
}

\section{RESUMO}

Este estudo teve como objetivos verificar as expectativas dos alunos quanto a: concepções sobre o Recém-nascido (RN), o que esperavam da disciplina de Enfermagem Neonatológica e, a visão que tinham da família do RN. Trata-se de um estudo exploratório-descritivo que foi desenvolvido com 33 alunos do Curso de Graduação em Enfermagem da Universidade Federal de São Carlos (UFSCar), no segundo semestre de 2007. Os resultados mostraram que as expectativas dos alunos, quanto à disciplina de Enfermagem Neonatológica, são de apreensão quando esses visualizam a fragilidade do RN e as dificuldades no manejo dos cuidados. Neste sentido, a figura do professor surge como a de um profissional que pode contribuir para que as dificuldades minimizem ou mesmo desapareçam. Também foi apontada a família como tendo um papel fundamental no atendimento ao RN.

Palavras chave: Educação em enfermagem; Neonatologia; Recém-nascido; Estudantes de enfermagem.

\section{ABSTRACT}

The aim of this study was the chek the student's expectations about the newborn-babies concepts, the course of Neontology Nursing, and their concepts of newborn baby family. This is an exploratory-descriptive study developed with 33 undergraduate students from São Carlos Federal University(UFSCar) Nursing Course during the second semester of 2007. The results showed that the student's expectations about the Neonatology Nursing Course are of apprehension when they visualised the newborn fragility and their difficulties with the handling of care measures. In this sense, the professor appears like a professional who can contribute in order to reduce or to make the difficulties disappear. The family was also considered to have an important role in the newborn baby attention.
Key words: Nursing education; Neonatology; Newborn; Students nursing.

\section{RESUMEN}

Este estudio tuvo como objetivos verificar las expectativas de los alumnos cuanto a: concepciones sobre el Recién-Nacido(RN), lo que esperavam de la disciplina de Enfermería Neonatológica y la visión que tenían de la familia del RN. Se trata de un estudio exploratorio-descriptivo que fue desarrollado con 33 alumnos del Curso de Graduación en Enfermería de la Universidad Federal de São Carlos (UFSCar), en el segundo semestre de 2007. Los resultados mostraron que las expectativas de los alumnos cuanto a la disciplina de Enfermería Neonatológica, son de aprensión cuando eses visualizan la fragilidad del RN y las dificuldades en el manejo de los cuidados. En esto sentido, la figura del maestro surge como la de un profesional que puede contribuir para que las dificuldades minimicen o mismo desaparezcan. La familia también fue apuntada como teniendo papel fundamental en la atención al RN.

Palabras clave: Educacíon en enfermería; Neonatología; Recién-nacido; Estudiantes de enfermería.

\footnotetext{
Enfermeira. Doutora em Enfermagem. Professora Adjunta Departamento de Enfermagem da Universidade Federal de São Carlos/UFSCar. E-mail: dmirb@.ufscar.br.

"Enfermeira. Doutora em Enfermagem. Professora Adjunta Departamento de Enfermagem da Universidade Federal de São Carlos/UFSCar. E-mail: silviazem@ufscar.br.

"II Enfermeira. Doutora em Enfermagem. Professora Adjunta Departamento de Enfermagem da Universidade Federal de São Carlos/UFSCar. E-mail: gdupas@ufscar.br.
} 
Beretta MIR, Mascarenhas SHZ, Dupas G. Expectativas dos alunos do curso de enfermagem acerca da disciplina de Enfermagem Neonatológica. Rev. Eletr. Enf. [Internet]. 2008;10(3):711-20. Available from: http://www.fen.ufg. br/revista/v10/n3/v10n3a17.htm.

\section{NTRODUÇÃO}

A área de Enfermagem Pediátrica vem passando por várias transformações desde sua implantação como disciplina obrigatória nos currículos da enfermagem brasileira até os dias de hoje. A implantação do conteúdo de enfermagem pediátrica no Brasil somente ocorreu a partir do currículo aprovado em 1949, o qual foi baseado no currículo norte-americano de 1937. Desde o início, o ensino da assistência à criança foi fundamentado no ensino de patologia e das técnicas de enfermagem para atender à criança doente ${ }^{(1)}$.

Entretanto, pode-se observar que, somente a intervenção e recuperação do corpo biológico da criança não têm respondido de forma plena às necessidades de saúde, pois estas vão além e demandam uma atenção que deve levar em conta a integralidade do ser humano, a qualidade de vida e a promoção da saúde ${ }^{(2)}$.

No processo de formação, ao invés de limitar-se apenas à profissionalização do indivíduo, existe a necessidade de se desenvolver o pensamento crítico. Para isso, a formação dos estudantes de enfermagem deve abranger aspectos da profissão, com o objetivo de valorizar as ações de enfermagem com humanização. Os cuidados a serem prestados à criança devem ser adequados ao seu contexto, atender as expectativas dos envolvidos, respeitando o nível de conhecimento e estabelecendo uma relação de afetividade com o outro no desempenho do cuidado ${ }^{(3)}$.

$\mathrm{Na}$ abordagem do ensino de enfermagem, é importante conhecer como o aluno vivencia a situação de aprendizagem, o que é significativo para ele e como percebe seu aprendizado, pois dessa forma, um passo importante é dado para a implementação de modificações e ajustes que permitam ampliar sua concepção e maneira de cuidar, indo além da patologia e das técnicas. Assim sendo, o aluno de enfermagem com o apoio do professor-facilitador tende a modificar seu olhar e papel profissional em relação à criança e família ${ }^{(4)}$.

A assistência de enfermagem à criança deve também, além de ter uma fundamentação científica, ter uma filosofia centrada não somente na patologia, mas também na criança e sua família(5). Além disso, é importante entender que as relações entre as famílias e os serviços de saúde estão inseridas em um conjunto de determinantes sociais, políticos e econômicos ${ }^{(2)}$.

Trazendo esses conceitos mais especificamente para a enfermagem neonatológica, compreendemos que o enfermeiro exerce um papel fundamental no nascimento de uma criança, podendo influenciar de maneira positiva o vínculo dos pais com o filho, permitindo que os primeiros minutos de vida do bebê se tornem uma experiência emocionante para todos. Quando os RNs são mantidos junto do corpo da mãe, aparentemente sentem-se seguros, reconhecem a voz e o cheiro da mãe e o corpo dela aquece o seu, fazendo com que a transição para a vida extra-uterina seja bem mais "agradável" e menos traumática. Assim, cabe a enfermagem proteger esse momento e permitir esse primeiro encontro íntimo, adiando o tempo possível, a realização dos procedimentos técnicos ${ }^{(6)}$.

O Curso de Enfermagem da Universidade Federal de São Carlos (UFSCar) foi criado em 1977. Os conteúdos de Pediatria e Neonatologia eram ministrados na disciplina de Enfermagem Obstétrica e, a partir de 1984, por meio de uma mudança curricular, passaram a compor disciplinas independentes, denominadas: "Enfermagem Pediátrica" e "Enfermagem Neonatológica". A disciplina de Enfermagem Neonatológica, cenário deste estudo, está inserida no sétimo semestre do curso (com carga horária de 60h, dividida em 30 horas teóricas e 30 horas de ensino clínico em instituições de saúde) e ocorre concomitante com as disciplinas Enfermagem Obstétrica e Enfermagem Pediátrica, de forma a ser considerada parte do núcleo materno-infantil.

$\mathrm{Na}$ década de noventa os alunos eram divididos em grupos de dez para a realização do ensino clínico, enquanto o conteúdo teórico era ministrado a todos os alunos simultaneamente. A avaliação da parte teórica era baseada em três avaliações dissertativas.

Em 1996 foi proposta uma nova forma de avaliação contínua, de modo a oferecer subsídios para o processo ensino-aprendizagem. Foram adotadas avaliações formativas que eram realizadas no início de cada aula, durante os primeiros trinta minutos, referentes ao 
Beretta MIR, Mascarenhas SHZ, Dupas G. Expectativas dos alunos do curso de enfermagem acerca da disciplina de Enfermagem Neonatológica. Rev. Eletr. Enf. [Internet]. 2008;10(3):711-20. Available from: http://www.fen.ufg. br/revista/v10/n3/v10n3a17.htm.

conteúdo da aula anterior com o objetivo de intensificar a retenção do conhecimento. Ao realizar-se uma comparação entre o desempenho dos alunos com este novo processo de avaliação e dos alunos com o processo de avaliação anterior, observou-se que não houve mudanças significativas que justificassem a implementação desta forma de avaliação ${ }^{(7)}$. Com relação ao ensino clínico, havia certo grau de insatisfação por parte das docentes responsáveis pela disciplina quanto ao grande número de alunos em campo, uma vez que isto dificultava o processo ensinoaprendizagem.

Após vários anos de discussões junto à chefia do departamento de enfermagem, houve a compreensão de que o número de alunos no campo devido às especificidades da disciplina deveria ser reduzido. A disciplina foi reestruturada e, atualmente, o ensino clínico é realizado na proporção de três alunos por docente.

Essa forma de trabalho, que envolve também a preocupação do aluno como pessoa, possibilitou maior contato das docentes com os alunos em situação de ensino-aprendizagem nos campos de ensino clínico, propiciando maior segurança para a realização dos procedimentos e ampliando as situações de discussão de casos clínicos.

Ao final do período do ensino clínico é realizada uma avaliação na qual os alunos podem colocar suas críticas e sugestões sobre o desenvolvimento da disciplina, bem como realizar uma auto-avaliação de seu desempenho nas diferentes situações vivenciadas. Com base na análise dos relatos dos alunos, a disciplina é reestruturada para a turma seguinte. $O$ conteúdo e as estratégias utilizadas na parte teórica da disciplina também são avaliados pelos alunos e docentes para contribuir no planejamento subseqüente da mesma.

Os docentes desta disciplina preocupamse em oferecer aos alunos uma formação que proporcione uma assistência de enfermagem humanizada ao RN (Recém-nascido) e sua família. Portanto, no seu desenvolvimento os alunos são orientados a valorizar o ser humano e a compreender a responsabilidade do cuidado à criança.
Além disso, os docentes envolvidos também procuram seguir as Diretrizes Curriculares do Curso de Enfermagem, ou seja, os alunos dos cursos de graduação em saúde devem aprender a aprender, o que engloba aprender a ser, aprender a fazer, aprender a viver juntos e aprender a conhecer, de forma a garantir a capacitação de profissionais com autonomia e discernimento para assegurar a integralidade da atenção e a qualidade e humanização do atendimento prestado aos indivíduos, famílias e comunidades ${ }^{(8)}$.

Os alunos, como a maioria dos leigos, temem até mesmo segurar um RN nos braços. No entanto, além de vencerem esta barreira, ainda necessitam apreender o conhecimento técnico-científico, bem como desenvolver habilidades específicas para esse cuidado tão peculiar, gerando muita ansiedade.

Com base no exposto, este estudo buscou conhecer as expectativas dos alunos quanto a: concepções sobre o RN, o que esperavam da disciplina de Enfermagem Neonatológica e, a visão que tinham da família do RN.

\section{METODOLOGI A}

O presente trabalho consiste em um estudo qualitativo, de cunho exploratório e descritivo, realizado com alunos de um curso de enfermagem de uma Universidade Pública Federal do interior do estado de São Paulo/SP (na Universidade Federal de São Carlos), no segundo semestre de 2007.

Os dados foram coletados por meio de questionário, com 33 alunos do terceiro ano do referido curso (Curso de Graduação em Enfermagem da UFSCar.) Estes se encontravam na faixa etária de 21 a 25 anos e, já haviam realizado atividades práticas em outras disciplinas, em unidades clínicas e cirúrgicas, inclusive cursado disciplinas relacionadas ao cuidado de enfermagem a crianças, tanto em creches como em Unidades Básicas de Saúde.

O estudo atendeu as normas da Resolução 196/96 que regulamenta pesquisas com seres humanos ${ }^{(9)}$. Portanto, somente foi realizado após obter aprovação do Comitê de Ética em Pesquisa em Seres Humanos da UFSCar (CAAE 0051.0.135.000-07).

Para a coleta de dados, utilizou-se a sala de aula, no primeiro dia da disciplina, antes que 
Beretta MIR, Mascarenhas SHZ, Dupas G. Expectativas dos alunos do curso de enfermagem acerca da disciplina de Enfermagem Neonatológica. Rev. Eletr. Enf. [Internet]. 2008;10(3):711-20. Available from: http://www.fen.ufg. br/revista/v10/n3/v10n3a17.htm.

se iniciasse qualquer atividade. Os alunos foram convidados a participar do estudo, sendo-lhes assegurados os princípios éticos da Resolução 196/96, garantindo-Ihes o anonimato de suas informações ${ }^{(9)}$. Foram feitos esclarecimentos quanto aos objetivos do estudo e a opção de participarem ou não.

O instrumento de coleta de dados (questionário) não continha campos de identificação e o preenchimento teve uma duração média de 30 a 40 minutos. O questionário abordou as seguintes questões norteadoras: Ao olhar para o Recém-nascido, o que você pensa a respeito dele? (foi projetada a figura de um RN em uma tela); Quais são suas expectativas a respeito da Disciplina de Enfermagem Neonatológica e o que você espera aprender nela? Quais são suas expectativas em relação aos docentes desta disciplina? Como você vê a família dentro da Enfermagem Neonatológica?

Os dados coletados foram organizados e agrupados por semelhanças, dando origem a várias categorias que foram sistematizadas utilizando-se a técnica de análise temática de Bardin, a qual consiste em descobrir os sentidos da comunicação que signifiquem algo para o objetivo final da pesquisa. A investigação dos temas ou análise temática foi o tipo de categorização adotado por ser rápido e eficaz na aplicação a discursos diretos e simples ${ }^{(10)}$.

Para análise dos dados as informações foram organizadas utilizando-se três pólos cronológicos previstos pela análise de conteúdo temática: a pré-análise (organização do material); a exploração do material (operação de codificação, classificação e categorização) e o tratamento dos resultados, inferência e interpretação (estabelecimento de relações por meio de reflexão e intuição) ${ }^{(10)}$.

\section{RESULTADOS E DISCUSSÃO}

As informações oriundas dos questionários foram organizadas e a análise dos dados permitiu a identificação de categorias em três grandes temas: "concepções acerca do RN", "visão da família" e "expectativas com relação à disciplina", conforme apresentadas a seguir.

\section{Concepções acerca do RN}

Nessa categoria foram incluídas as seguintes unidades temáticas: Símbolo de uma nova vida; Fragilidade e exigência de cuidados do RN; e RN como um ser humano.

\section{Símbolo de uma nova vida}

Os alunos, por ainda não terem vivenciado a maternidade, parecem somente perceber os aspectos relacionados à alegria e felicidade que um bebê traz para os pais e familiares. Pelos relatos, pode-se perceber que ainda não têm percepção das inúmeras variáveis, como sentimentos, modificações, desafios e responsabilidades, que envolvem a gravidez e o nascimento.

“O RN representa vida nova, alegria para o casal e família". (A1)

"Penso que ele é uma nova vida, indefeso, que necessita de proteção, amor, compreensão e cuidados para se desenvolver e passar pelas fases de sua vida". (A29)

"Que ele é o símbolo de uma nova vida, um novo ser humano no espaço terrestre, uma pessoa que vai crescer, desenvolver, reproduzir e morrer. E em todo esse contexto passará por muitos sofrimentos, alegrias, emoções, ilusões, assim como todo ser humano passa no decorrer de sua vida". (A11)

"Uma nova vida, a qual tem muita importância". (A6)

Desde o início da gravidez a vida da mulher passa por mudanças significativas, tanto físicas como psicológicas. Estabelece-se uma relação imaginária com o feto, com sentimentos ambivalentes, seja a gravidez planejada ou não. Ao mesmo tempo em que a mãe está alegre com o fato de gerar um filho e deseja poder cuidar dele de maneira adequada, surgem temores relacionados à saúde do mesmo e das alterações do estilo de vida conseqüentes da maternidade ${ }^{(11)}$.

Por outro lado, além do simbolismo da vida, percebe-se também por parte dos alunos uma preocupação com a fragilidade do RN que terá pela frente todo o ciclo de um ser humano. Tal percepção foi detectada quando alguns deles revelaram preocupações em relação à fragilidade do $\mathrm{RN}$ e os cuidados a serem 
Beretta MIR, Mascarenhas SHZ, Dupas G. Expectativas dos alunos do curso de enfermagem acerca da disciplina de Enfermagem Neonatológica. Rev. Eletr. Enf. [Internet]. 2008:10(3):711-20. Available from: http://www.fen.ufg. br/revista/v10/n3/v10n3a17.htm.

prestados a estes ao verem uma figura de Recém-nascido.

\section{Fragilidade e exigência de cuidados do RN}

A fragilidade é uma peculiaridade do RN que desperta emoções nos alunos e o torna alvo de atenção. Ao proceder a análise das falas, pode-se observar que a forma de pensar dos alunos é muito semelhante ao de uma mãe que tem um filho, ou seja, eles parecem ter o instinto materno de proteção do filho, por ser considerado frágil e indefeso, totalmente dependente de cuidados.

Talvez, pelo fato do ser humano ser a espécie mais dependente que existe na natureza, os alunos já tenham uma noção de que a condição de vulnerabilidade da criança implicará na necessidade de assisti-la com segurança e conhecimento de todas as suas especificidades. Os relatos, além de ressaltarem estes aspectos, também salientam que o RN necessita de muito cuidado e carinho para se adaptar ao novo ambiente.

Penso a respeito de sua fragilidade. Ele é tão pequeno e depende muito dos outros para crescer. (A2)

Que é um ser pequenininho, indefeso, delicado, frágil, mas encantador e que deve despertar emoções fortíssimas na mãe ao ser recebido por ela. (A23)

O RN parece frágil, dócil, que traz muitas mudanças na vida das pessoas. (A7)

Penso que é um ser frágil, indefeso, lindo que vai precisar de muito zelo, carinho e cuidado. (A16)

Uma nova pessoa que tem uma vida inteira pela frente e que precisa de cuidados para estar bem preparada para vivê-la. (A32)

É um ser lindo, fofo, frágil, criação de Deus! (A14)

Um ser frágil, assustado com a mudança do ambiente de vida e que precisa de muitos cuidados e carinho para se adaptar ao novo contexto. (A3)

Um ser que depende durante o princípio de sua vida, de muito cuidado. (A30)

Ao nascimento ocorrem inúmeras alterações no organismo da criança, que a partir desse momento, vai precisar funcionar em condições muito diferentes. Inúmeras funções passarão a ser utilizadas para a sobrevivência da criança, funções estas até então não solicitadas pelo organismo. Essas transformações criam o caráter da criança, sua vulnerabilidade, a qual exige cuidados específicos para que possa se adaptar às novas condições $^{(12)}$.

Os cuidados prestados ao bebê na ocasião do parto e as sensações provenientes deste momento têm um significado importante para as mães, sendo que a aproximação de mãe e filho no pó-parto imediato pode ficar na dependência da conduta do profissional que atende a mulher no processo de parturição ${ }^{(13)}$.

A vulnerabilidade da criança é muito maior do que a dos adultos, pelas próprias dificuldades em adaptar e coordenar as funções que passam a ser solicitadas. Isso exige uma assistência mais pronta e vigilante ${ }^{(12)}$.

Apesar dos sentimentos de felicidade que a mãe possa demonstrar ao nascimento de seu filho, existe geralmente uma preocupação com relação aos cuidados que ela deverá ter com o RN. A mãe pode ter receio em expor os sentimentos, principalmente o medo de não saber como cuidar do filho. No entanto, ninguém mais do que ela saberá comunicar-se com o filho nos primeiros meses de vida, pois têm uma ligação que foi construída durante toda a gestação.

Os alunos, embora não tenham essa ligação e muitas vezes possam não entendê-la, possuem uma preocupação com a fragilidade do RN e, diante disso, revelam apreensão e muita responsabilidade quanto ao cuidado do RN, conforme se pode observar nos relatos a seguir.

Penso a respeito da vida, da necessidade de cuidados, de proteção, de carinho. Penso também em alegrias e conquista de um sonho. (A27)

Um novo ser humano que precisa de vários cuidados e muito carinho para ter um desenvolvimento saudável. (A31)

Um ser frágil que precisa de cuidados especiais. (A15)

Um ser que precisa de cuidados especiais e dispensada toda atenção a essa criaturinha maravilhosa. (A24) 
Beretta MIR, Mascarenhas SHZ, Dupas G. Expectativas dos alunos do curso de enfermagem acerca da disciplina de Enfermagem Neonatológica. Rev. Eletr. Enf. [Internet]. 2008;10(3):711-20. Available from: http://www.fen.ufg. br/revista/v10/n3/v10n3a17.htm.

Para os pais, o bebê anuncia sua existência muito antes do nascimento e, os projetos e expectativas que envolvem a sua chegada são diversos e importantes de serem compreendidos.

O nascimento é um momento de encontro e comunicação entre o $\mathrm{RN}$ e a mãe, sendo que nas primeiras horas após o parto, 0 bebê nascido em boas condições, está num estado especial de alerta, que permite estabelecer um contato íntimo com a mãe traduzindo sua acolhida em seu novo mundo ${ }^{(14)}$.

Os cuidados com o RN começam no acompanhamento pré-natal e se intensificam no momento do nascimento, após uma longa espera. Muitas vezes a mãe precisa ser preparada para cuidar de seu próprio filho, pois somente o desejo de tê-lo não significa que esteja apta para realizar os cuidados necessários.

O ensino de enfermagem busca capacitar o profissional à prestação de cuidado de saúde ao ser humano-paciente-cliente, à realização e aperfeiçoamento de tecnologias e procedimentos que promovam a saúde. Para tanto, deverá estar assegurado um embasamento científico e o desenvolvimento de habilidades técnicas para atender às necessidades do outro, inerentes ao exercício da profissão ${ }^{(15)}$.

Ao vivenciar a experiências do cuidar, o aluno percebe o quanto é difícil cuidar da criança nos mais diferentes contextos, que é preciso ganhar a confiança tanto da criança como da família, ampliando desta forma, sua concepção e maneira de cuidar, indo além da patologia e das técnicas ${ }^{(4)}$.

Os alunos, apesar de não terem vivenciado os projetos e expectativas dos pais, terão a sua frente o RN que precisará receber seus cuidados. Chama a atenção o fato de que eles não se detêm nesse momento somente às necessidades fisiológicas do RN, mas também se preocupam com a "pessoa" que ele representa.

\section{RN como um ser humano}

Alguns alunos parecem conseguir visualizar o RN como um ser com identidade e não somente um ser que simboliza a vida e inspira cuidado, conforme relatos a seguir:
Como um ser humano capaz de manifestar suas emoções, vontades, reclamações; dependente principalmente da mãe que é com quem criou seu primeiro vínculo ao chegar ao mundo.(A17) Penso que ele é um ser humano tão pequeno e que já é capaz de interagir com sua mãe e com - mundo, através da expressão de suas vontades, da dor, do choro. (A26)

Ao se encontrar com um bebê, o estudante deve aprender também a olhar para dentro de si mesmo. Isso provavelmente fará com que ele tente conhecer um pouco mais o mundo de suas emoções a fim de aprender a lidar melhor com os aspectos emocionais do RN.

Para que isto ocorra, torna-se imprescindível que o processo de formação e capacitação de recursos humanos esteja ligado ao desenvolvimento do raciocínio crítico do aluno para que seja capaz de articular seus pensamentos e idéias para o cuidado integral ao RN. Portanto, sua formação deveria estar, igualmente, voltada às necessidades do ser humano e, não apenas à técnica, à cientificidade, à competitividade ou a excelência do cuidado prestado ${ }^{(15)}$.

Ao prestar assistência, o aluno torna-se mais sensibilizado ao cuidado quando identifica nas interações com a criança e família os elementos do cuidar, tendo a oportunidade de ampliar o conceito de cuidar. Como conseqüência, vai modificando a maneira de cuidar da criança e da família, sentindo-se importante no cuidado e recompensado por cumprir sua tarefa ${ }^{(4)}$.

Diante disso, supõe-se que, o aluno ao acompanhar uma mãe e seu bebê, deverá aprender a valorizar a relação e o vínculo entre os dois que, ou já está visível ou está se formando. Os alunos deverão ter a figura da mãe como referência, bem como conseguir visualizar o RN como parte integrante da família.

\section{Visão da família}

Essa categoria foi composta pelas seguintes unidades temáticas: "papel da família", "família no desempenho de cuidados ao RN e como colaboradora da equipe". 
Beretta MIR, Mascarenhas SHZ, Dupas G. Expectativas dos alunos do curso de enfermagem acerca da disciplina de Enfermagem Neonatológica. Rev. Eletr. Enf. [Internet]. 2008;10(3):711-20. Available from: http://www.fen.ufg. br/revista/v10/n3/v10n3a17.htm.

\section{Papel da família}

De acordo com os relatos a seguir, observa-se que alguns alunos encaram a família com tendo um papel fundamental tanto para o RN, como para a mãe.

A família é o mais importante para o RN, já que este depende dela para tudo (crescimento, desenvolvimento). E este também é o momento de estabelecer um vínculo ou fortalecê-lo entre o RN e família. (A4)

A família é essencial no acolhimento, proteção e cuidado desse ser para que ele possa se desenvolver de forma saudável no sentido integral (fisiologicamente, psicologicamente e socialmente). (A20)

A família é fundamental, servindo de estrutura, base e referência. (A12)

A família possui papel fundamental no acolhimento do bebê que acabou de "chegar" e desempenha papel importante para auxiliar e confortar a puérpera na sua nova vida. (A22)

Existe uma preocupação dos alunos, tanto em relação à família ser importante para o RN no momento do seu nascimento, quanto para seu crescimento e desenvolvimento.

Atualmente vários teóricos têm se empenhado em diferentes conceituações de família e enfermagem na assistência à família, colocando o cuidado de acordo com o modelo utilizado. Tanto pode ser direcionado ao indivíduo no contexto da família, como é a família com o indivíduo como contexto, sendo a tendência emergente a família como unidade do cuidado $^{(2)}$.

O nascimento de um filho passa a exigir da família novas estratégias para lidar com as tarefas de desenvolvimento, capacidade de adaptação para receber o novo membro e habilidades para administrar novas necessidades. Uma das tarefas dos genitores nesse período é buscar o equilíbrio do sistema familiar ${ }^{(16)}$.

\section{Família no desempenho de cuidados ao RN e como colaboradora da equipe.}

Pelos relatos abaixo, observa-se o fato dos alunos sentirem a responsabilidade de orientar a família quanto aos cuidados com o RN, pois têm a consciência que será ela que assumirá esse papel.

É também muito importante que a família seja bem orientada quanto aos cuidados com o novo membro. (A19)

Vejo a família como uma peça muito importante, pois as orientações serão dadas a ela e será ela a responsável pelo cuidado e carinho que será dado ao neonato. (A8)

A família é algo muito importante e que deve ser considerada sempre, pois dependemos muito dela para auxiliar-nos nos cuidados com o RN. (A21)

Os alunos ao se preocuparem com a orientação sobre os cuidados do RN a serem desempenhados pela família, passam a considerá-la como sua aliada, fazendo parte da equipe.

Ao se relacionar com a família e perceber a importância da interação enfermeiro-criançafamília, o vínculo que 0 aluno passa a estabelecer com a família o faz perceber que é preciso elevá-la à condição de parceira do cuidado, saindo de uma posição passiva, para sujeito do próprio cuidado ${ }^{(4)}$.

Através dos seus relatos observa-se a importância da família para a equipe de enfermagem/saúde, conforme se observa a seguir.

Eu imagino que a família deve ser preparada para a chegada do RN e assistida pela equipe de saúde neste sentido. (A13)

Acredito que a família é um ponto muito importante da disciplina, pois é ela quem será responsável por zelar por este RN após a alta do hospital. (A18)

A tendência de aproximação entre a família e as instituições de saúde, disseminouse a partir do final do século XVII nas sociedades ocidentais européias. No Brasil, esse movimento acentuou-se somente a partir de meados do século XIX, mas, assim como na Europa, mostrou-se fundamental para a modernização da sociedade. As condições sociopolíticas e econômicas do Brasil certamente imprimiram ao movimento características particulares, mas não diminuíram 
Beretta MIR, Mascarenhas SHZ, Dupas G. Expectativas dos alunos do curso de enfermagem acerca da disciplina de Enfermagem Neonatológica. Rev. Eletr. Enf. [Internet]. 2008;10(3):711-20. Available from: http://www.fen.ufg. br/revista/v10/n3/v10n3a17.htm.

a importância da aproximação Estado/medicina/família nesse processo ${ }^{(17)}$.

No contexto atual da saúde, a família deve ser reconhecida como ponto de partida para a melhoria das condições dos indivíduos, fundamentadas na promoção de conhecimento para o bem-estar. A enfermagem destaca-se como profissão dotada de características específicas, capazes de realizar a promoção integral á saúde que se inicia com o trabalho preventivo $^{(18)}$.

A preocupação dos alunos vai além dos cuidados ao RN e a interação da família, se estendendo também para situações de aprendizagem, que para alguns pode gerar expectativas de que a disciplina irá proporcionar os conhecimentos essenciais para seu desempenho, enquanto para outros, a disciplina representa temor.

\section{Expectativas com relação à disciplina}

As seguintes unidades temáticas compõem essa categoria: "aspectos positivos da disciplina", "temor da disciplina", "aprendizagem centrada no professor".

\section{Aspectos positivos da disciplina}

Os alunos, na condição de aprendizes, buscam através da disciplina, um aprendizado que thes proporcione condições de assistência na área. Se por um lado se preocupam com a necessidade de cuidados que o RN exige, por outro, esperam que a disciplina lhes forneça os subsídios para suprir esta deficiência e dessa forma, possam desempenhar a assistência de enfermagem ao RN, conforme se observa nos relatos a seguir:

Tenho ótimas expectativas a respeito da disciplina, pois espero aprender a dar assistência de enfermagem ao $\mathrm{RN}$ e à sua família, aplicar as ações de enfermagem, os cuidados e orientação. (A5)

Espero aprender a prestar os cuidados de Enfermagem ao neonato, assim como lidar com dificuldades ou complicações relacionadas a ele. A expectativa é positiva e a ansiedade é grande. (A10)

Minhas expectativas em relação à disciplina são poder vivenciar este período do nascimento e dessa forma poder oferecer todos os cuidados necessários. Espero aprender a melhor forma de oferecer esses cuidados sempre envolvendo em meu trabalho a mãe que é personagem importante. (A 33)

O ensino na área da saúde e, mais especificamente, no curso de graduação em enfermagem, deve propiciar aquisição de conhecimentos e mudanças comportamentais, que possibilitem o vínculo entre teoria e prática. A prática, ou seja, o desenvolvimento do ensino clínico deve significar o momento de junção teoria/prática, implicando na utilização de conceitos abstratos em situações concretas ${ }^{(19)}$.

Entretanto, ao considerarem as especificidades do RN, alguns alunos encaram a disciplina com temor, pois ao se darem conta que terão que enfrentar a fragilidade do Recémnascido, começam a ter noções de que o cuidado irá exigir muita responsabilidade.

\section{Temor da disciplina}

O temor da disciplina pode ser visualizado nas falas quando os alunos ressaltam a fragilidade do RN como um fator importante e decisivo para sua aprendizagem:

Estou com um pouco de medo na disciplina, porque o bebê é uma pessoa pequena, que não fala, delicada. Espero me superar nas dificuldades e, aprender as ações de enfermagem que envolvem todo o cuidado desde banho até ações mais complexas. (A14) Eu estou com medo da disciplina. Espero conseguir enfrentar minhas dificuldades, esclarecer sempre todas as minhas dúvidas e, aprender sobre os cuidados com o RN, ajudando a conservar e melhorar as condições de saúde desse novo ser humano tão frágil, que está chegando no mundo. (A23)

Através dos relatos, observa-se que alguns alunos além de manifestarem temor pela disciplina, pelo fato do $\mathrm{RN}$ exigir cuidados complexos, também estão preocupados com as suas dificuldades e esperam que estas sejam superadas. Alguns deles também depositam suas expectativas de aprendizagem na figura do professor. 
Beretta MIR, Mascarenhas SHZ, Dupas G. Expectativas dos alunos do curso de enfermagem acerca da disciplina de Enfermagem Neonatológica. Rev. Eletr. Enf. [Internet]. 2008;10(3):711-20. Available from: http://www.fen.ufg. br/revista/v10/n3/v10n3a17.htm.

\section{Aprendizagem centrada no professor}

O professor passa a ser visto como uma referência. O conhecimento se concretizará através dele, conforme se pode observar nos seguintes relatos:

Espero aprender, que o professor consiga me ensinar toda a assistência de enfermagem ao neonato e todas as atividades do enfermeiro. (A2)

Espero que o docente consiga transmitir as informações necessárias para minha formação. Que eu seja capaz de assimilar bem o conteúdo dado pelo docente. (A19)

No processo da formação pedagógica dos alunos de enfermagem, sempre está presente por parte das docentes da disciplina de Enfermagem Neonatológica a preocupação com a aprendizagem dos alunos. Este fato leva a uma busca cada vez maior de recursos que possam contribuir para sua formação.

O docente necessita estar ciente das dificuldades e procurar atuar como facilitador do processo de articulação entre teoria e prática, com conhecimentos e habilidades pedagógicas necessárias para motivar o aluno de maneira efetiva(5). Por outro lado, o aluno atribui seu crescimento e a aprendizagem ao professor quando este atua como facilitador do aprendizado, com atitudes ponderadas e relacionamento de igual para igual com os alunos, sem julgamentos ou pressões, conduzindo o processo de aprendizagem com tranqüilidade ${ }^{(4)}$.

O professor ideal seria aquele que conhece a disciplina que leciona, tem clareza e linguagem fácil em suas explicações, admite e demonstra haver maneiras diferentes de ensinar, demonstra segurança e domínio de si na condução do ensino. Os aspectos afetivos do relacionamento professor-aluno são mediadores, para que, através dos domínios do conteúdo específico da disciplina e dos aspectos didático-pedagógicos, o processo ensinoaprendizagem se concretize com sucesso(20).

Os alunos projetam no docente uma expectativa de aprendizagem não somente para proporcionar os cuidados ao RN, mas também uma aprendizagem voltada para sua formação, além de projetá-la na sua decisão profissional.

\section{CONSI DERAÇÕES FI NAIS}

Os dados levantados possibilitaram uma visualização dos conteúdos fundamentais que deverão ser ministrados na disciplina, bem como a necessidade de desenvolver novas estratégias de ensino. Embora os docentes, pela vivência acadêmica, já tivessem percepção das dificuldades nos cuidados com o RN, o fato dos alunos evidenciarem este tipo de preocupação provoca uma reflexão maior a respeito de como proporcionar aos alunos um aprendizado com mais segurança. Isso pode garantir que, as diretrizes curriculares não fiquem somente no papel e que, a disciplina não faça simplesmente parte de uma grade, mas proporcione conhecimento que contribua para o crescimento pessoal e direcione uma decisão profissional após a realização da mesma.

A preocupação em relação às dificuldades nas habilidades dos alunos para os cuidados ao RN, exige uma reorganização do cronograma sobre os conteúdos ministrados, de forma que contemple as necessidades relatadas por estes. Leituras complementares e busca por informações e conhecimentos adicionais são incentivados, para que os alunos possam ter um elo maior entre a teoria e a prática, de modo a adquirir segurança no ensino clínico para o fortalecimento de sua prática profissional.

Com relação à família, foi visto que os alunos já tinham entendimento que esta desempenhava um papel muito importante neste processo. Estes conseguiram visualizar que o RN não era um paciente único, mas fazia parte de um contexto denominado família que tinha estrutura, dava carinho, mas também necessitava de orientações da equipe de enfermagem e que, portanto, poderia ser um aliado fundamental na neonatologia. Este fato evidenciou que os docentes ao ministrarem a disciplina, ao invés de colocarem os conceitos básicos da participação da família, poderiam aprofundar esta prática.

Vários alunos manifestaram temor pela disciplina e projetaram na figura do professor, a expectativa pelo seu aprendizado e a aquisição de habilidades no manejo do RN. Isso leva a uma reflexão sobre a importância do professor não ser simplesmente um veículo de transmissão de conhecimento, mas sim, além de ter o domínio, ter a didática, bem como 
Beretta MIR, Mascarenhas SHZ, Dupas G. Expectativas dos alunos do curso de enfermagem acerca da disciplina de Enfermagem Neonatológica. Rev. Eletr. Enf. [Internet]. 2008;10(3):711-20. Available from: http://www.fen.ufg. br/revista/v10/n3/v10n3a17.htm.

também um envolvimento afetivo que proporcione ao aluno, tanto a liberdade de se manifestar, como a de ser ouvido.

Acredita-se que, se os aspectos levantados pelos alunos forem levados em consideração para o próximo oferecimento da disciplina, permitir-se-á a inserção dos mesmos de forma mais ativa no processo de aprendizagem. De igual forma, poderá lhes proporcionar maior satisfação na realização das atividades programadas e despertar consciência crítica, que os auxilie a alicerçar uma nova enfermagem.

\section{REFERÊNCI AS}

1. Collet N, Rocha SMM. Transformações no ensino das técnicas em enfermagem pediátrica. Goiânia: AB; 1996.

2. Rocha SMM, Nascimento LC, Lima RAG. Enfermagem pediátrica e abordagem da família: subsídios para o ensino de graduação. Rev Latino-am Enfermagem. 2002; 10(5): 709-14.

3. Oliveira AAP, Ribeiro MO. O cuidar da criança de/na rua na perspectiva dos graduandos de enfermagem. Texto contexto-enferm. 2006; 15(2): 246-53.

4. Pettengill MAM, Nunes CB, Barbosa MAM. Professor e aluno compartilhando da experiência de ensino-aprendizagem: a disciplina de enfermagem pediátrica da Universidade Federal de Mato Grosso do Sul. Rev Latino-am Enfermagem. 2003; 11(4):453-60.

5. Cintra SMP, Silva CV, Ribeiro CA. O ensino do brinquedo/brinquedo terapêutico nos cursos de graduação em enfermagem no Estado de São Paulo. Rev Bras Enferm. 2006; 59(4):497-501.

6. Klaus $\mathrm{MH}$, Klaus $\mathrm{PH}$. Seu surpreendente recém-nascido. Porto Alegre: Artmed; 2001.

7. Dupas G, Beretta MIR. Utilizando uma nova forma de avaliação do conteúdo teórico da disciplina Enfermagem Neonatológica: relato de experiência. Acta paul. enferm. 1996;9(Número Especial): 102-3.

8. Ministério da Educação; Conselho Nacional de Educação, Câmara de Educação Superior. PARECER №: CNE/CES 1.133/2001. Diretrizes curriculares nacionais dos cursos de graduação em enfermagem, medicina e nutrição. Brasília: Diário Oficial da União de 3/10/2001 [Internet]. Seção 1E, p. 131. 2001 [cited 2007 set 10]. Available from: http: //portal. mec.gov. br/cne/arquivos/pdf/CES1 133.pdf.
9. Ministério da Saúde; Conselho Nacional de Saúde. Resolução 196 de 10 de outubro de 1996. Diretrizes e normas regulamentadoras da pesquisa envolvendo seres humanos. Brasília (Brasil): Ministério da Saúde; 1996.

10. Bardin L. Análise de conteúdo. 3ạ edição. Lisboa: Edições 70; 2004.

11. Needlman RD. O recém-nascido. In: Behrman RE, Kliegman RM, Jenson $H B$, editores. Nelson - Tratado de pediatria. Tradução de Marcio Moacyr de Vasconcelos. Rio de Janeiro: Guanabara Koogan; 2002. p.31-3.

12. Marcondes E, Vaz F, Ramos JLA, Okay Y. Pediatria básica. Tomo I - Pediatria geral e neonatal. São Paulo: Sarvier; 2002.

13. Cruz DCS, Sumam NS, Spíndola T. Os cuidados imediatos prestados ao recém-nascido e a promoção do vínculo mãe-bebê. Rev. esc. enferm. USP. 2007;41(4):690-7.

14. Maldonado MT. Psicologia da gravidez, parto e puerpério. São Paulo: Saraiva; 2000.

15. Baggio MA. O significado de cuidado para profissionais da equipe de enfermagem. Ver. Eletr. Enferm. [Internet] 2006 [cited 2007 set 10];8(1):9-16. Available from: http://www.fen.ufg.br/revista/revista8 1/origin al 01.htm.

16. Dessen MA, Braz M. Rede social de apoio durante transições familiares decorrentes do nascimento de filhos. Psic.: Teor. e Pesq. 2000; 16(3): 221-31.

17. Braga MGR, Amazonas MCLA. Família: maternidade e procriação assistida. Psicol. estud. 2005; 10(1): 11-8.

18. Weirich CF, Tavares JB, Silva KS. O cuidado de enfermagem à família: um estudo bibliográfico. Ver. Eletr. Enferm. [Internet] 2004 [cited 2007 set 10];6(2):172-180. Available from:

http://www.fen.ufg. br/revista/revista6_2/cuida do.html.

19. Valsecchii EASS, Nogueira MS. Fundamentos de Enfermagem: incidentes críticos relacionados à prestação de assistência em estágio supervisionado 1. Rev Latino-am Enfermagem 2002; 10(6):819-24.

20. Worschech J M, Pelá NTR. O professor real e o ideal na visão de um grupo de graduandos de enfermagem. Rev. esc. enferm. USP. 2004; 38(2): 168-74.

Artigo recebido em 20.09.07

Aprovado para publicação em 30.09.08 